\title{
РОЛЬ РОЗНИЧНОЙ ТОРГОВЛИ В РАЗВИТИИ НАЦИОНАЛЬНОЙ ЭКОНОМИКИ РЕСПУБЛИКИ БЕЛАРУСЬ
}

\author{
И. А. Кулаков ${ }^{1}$, Л. О. Кулакова ${ }^{2}$ \\ ${ }^{1}$ Старший преподаватель кафредры менеджмента учреждения образования \\ «Брестский государственный технический университет», Брест, Беларусь, e-mail: kulakou1965@таil.ru \\ ${ }^{2}$ Старший преподаватель кафедры управления, экономики и финансов учреждения образования \\ «Брестский государственный технический университет», Брест, Беларусь, e-mail: lejla67@mail.ru
}

\begin{abstract}
Реферат
Целью данной работы является изучение современного состояния розничной торговли Республики Беларусь и разработка перспективных направлений её развития.

Объект исследования - розничные торговые предприятия Республики Беларусь.

Ритейл Республики Беларусь имеет свои особенности. Например, нормативное регулирование ассортимента и ценообразования, наличие социально значимых товаров, осуществление закупок за собственные средства с приоритетом прямых связей и ограничением доступа субъектов хозяйствования к торгам.

Розничная торговля стимулирует развитие экономики Республики Беларусь, увеличивая сбыт на предприятиях, что снижает издержки обращения, себестоимость и повышает конкурентоспособность товаров.

Необходимо развивать новые формы взаимоотношений торговли с товаропроизводителями - улучшение маркетингового обслуживания предприятий промышленности, заключение долгосрочных соглашений, совершенствование фирменной торговли, создание торговопромышленных групп, внедрение франчайзинга, развитие прямые хозяйственных связей с промышленными производителями, сельхозпредприятиями и фермерскими хозяйствами.
\end{abstract}

Ключевые слова: розничные торговые предприятия, розничная торговля, цепочки поставок, ритейл, ритейлеры, товаропоток, товарооборот.

\section{ROLE OF RETAIL TRADE IN THE DEVELOPMENT OF THE NATIONAL ECONOMY OF THE REPUBLIC OF BELARUS}

\section{Abstract}

\section{A. Kulakou, L. O. Kulakova}

The purpose of this work is to study the current state of retail trade in the Republic of Belarus and develop promising directions for its development. The object of research is retail trade enterprises of the Republic.

Retail in the Republic of Belarus has its own characteristics. For example, the normative regulation of the assortment and pricing, the availability of socially significant goods, the implementation of purchases for their own funds with the priority of direct links and restricting the access of business entities to trading.

It is necessary to develop new forms of relationships between retailers and manufacturers - improving marketing services for industrial enterprises, concluding long-term agreements, improving corporate trade, creating commercial and industrial groups, introducing franchising, developing direct economic ties with industrial producers, agricultural enterprises and farms.

Keywords: retail trade enterprises, retail, supply chains, ri-tailers, commodity flow, trade turnover.

\section{Введение}

Розничная торговля - это вид торговли товарами, предназначенными для семейного, личного, домашнего потребления или иного подобного пользования, не связанного с предпринимательской деятельностью. Здесь завершается процесс обращения товаров и доведение их до покупателей.

Основной задачей розничной торговли является удовлетворение растущих потребностей населения. Для этого розничная торговля нуждается в рациональной организации коммерческой деятельности, которая состоит из следующих этапов:

1) изучение потребительского спроса, требований к товарам, мотивов покупок, особенностей покупательского поведения;

2) определение объема и структуры спроса на товары и услуги;

3) организация процесса продажи и стимулирование объемов продаж;

4) формирование конкурентоспособного ассортимента;

5) рекламно-информационная деятельность;

6) услуги и сервисное обслуживание.

Необходимым условием ритмичной, бесперебойной работы розничного предприятия является рациональное товароснабжение. Значительная часть товаров поступает в розничную торговую сеть от оптовых предприятий. Обеспечивающими структурами остальных, входящих в ритейл товаропотоков являются производственные, заготовительные предприятия, подсобные и фермерские хозяйства, а также индивидуальные предприниматели.
Целью данной работы является анализ деятельности розничной торговли в Республике Беларусь на современном этапе развития экономики, выявление основных проблем, тенденций, а также влияния данного сектора экономики на благосостояние общества в целом и на потребителя в отдельности, предложение возможных путей совершенствования представляемых услуг с точки зрения экономических и этических подходов. Объектом анализа являются предприятия розничной торговли на современном этапе развития экономики Республики Беларусь.

Теоретико-методологическая основа анализа товаропроводящих систем на розничном рынке наиболее обстоятельно и всесторонне представлена в трудах белорусских ученых - Виноградовой С. Н., Егорова В. Ф., Пигуновой Н. Г., Кабушкина Н. И., а также в трудах зарубежных исследователей, таких как Дашков Л. П., Памбухчиянц Л. П., Ковалев К. Ю., Даненбург В., Кент Т.

\section{Розничная торговля в Республике Беларусь}

Основными принципами коммерческой деятельности на розничном предприятии являются: соблюдение действующего законодательства; высокая культура обслуживания покупателей; оптимальность коммерческих решений; доходность, прибыльность [1].

С учетом экономических параметров рынка и целевой предназначенности розничного торгового предприятия на коммерческую деятельность этого субъекта хозяйствования возлагается выполнение следующих функций: 


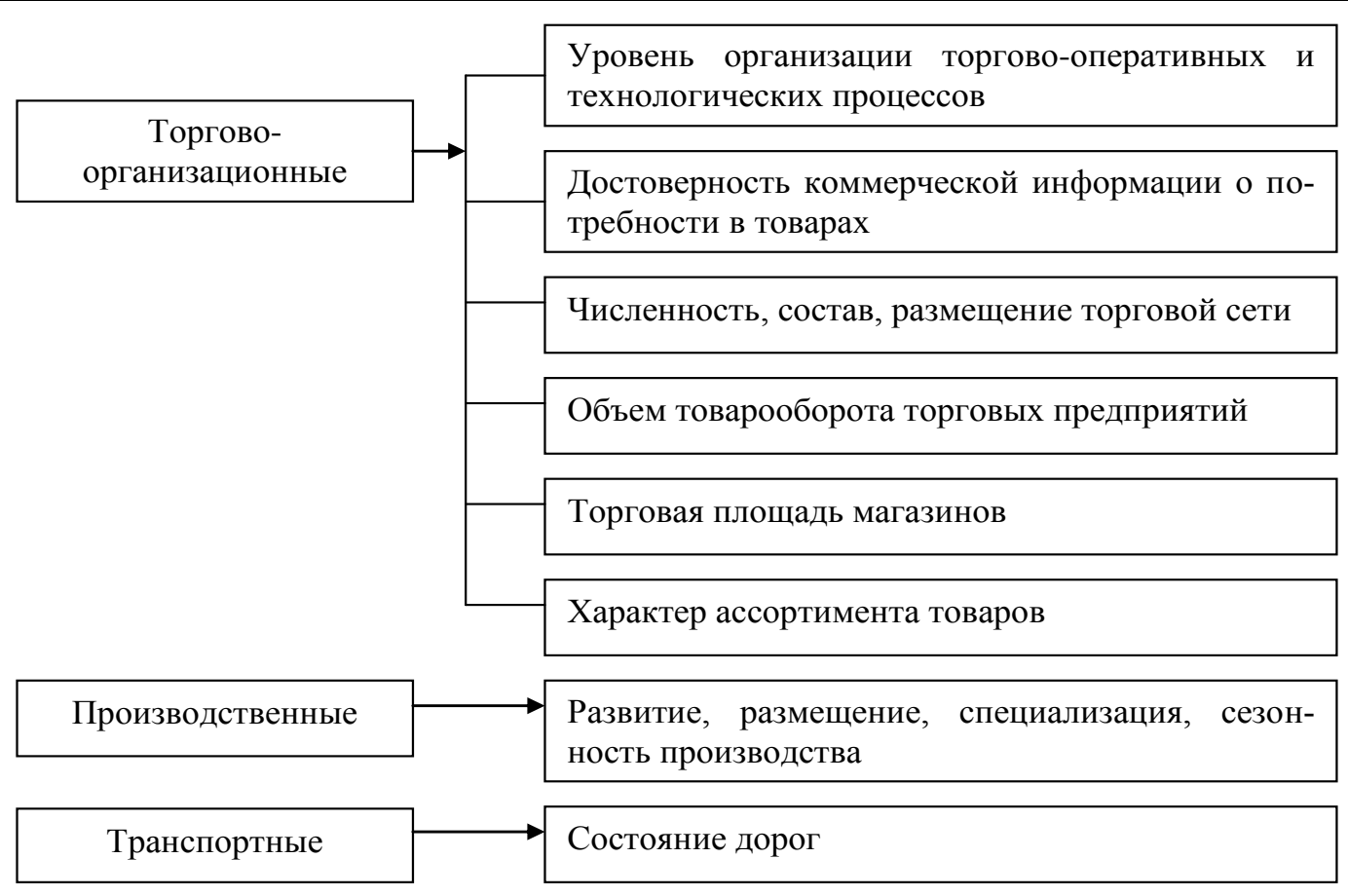

Рисунок 1 - Факторы, влияющие на организацию товароснабжения

1) формирование коммерческой политики, т. е. определение текущих и перспективных задач коммерческой деятельности, способов их решения;

2) комплексный подход к коммерческой работе, предполагающий слаженную, оптимально скоординированную работу коммерческих звеньев торгового предприятия как единого механизма;

3) гибкое, адаптивное управление куплей-продажей товаров с использованием инструментов маркетинга и современных бизнестехнологий;

4) развитие рынков товаров на основе маркетинговых исследований, зондирования и тестирования рынка, выявления тенденций, трендов, специфики и перспектив его роста;

5) адаптация механизмов и технологий коммерции к динамике внешней среды;

6) обеспечение строгого учета и контроля издержек, связанных с коммерческой деятельностью, оптимальность которых определяется их запаздывающим темпом роста по отношению к темпу роста доходов, получаемых в результате такой деятельности.

Ключевые факторы, влияющие на организацию товароснабжения, представлены на рисунке 1.

Развитию розничной торговли в Республики Беларусь придаётся огромное значение, поскольку речь идёт о постоянно растущем спросе граждан страны. В торговой сфрере динамично формируются торговые и товаропроводящие сети, обновляется материально-техническая база, происходит расширение специализированных и фирменных магазинов, развиваются новые формы и методы продаж, информационные технологии. Огромная роль ритейла выражается в том, что он является одним из основных источников поступления денежных средств и, соответственно, влияет на развитие экономики и наполняемость бюджета. Поступления в бюджет создают условия для развития социальной сфреры, реализации наиболее важных государственных программ. Огромную роль в развитии розничной торговли играет логистика, что в полной мере отражено в «Концепции развития логистической системы Республики Беларусь до 2030 года» [2].

В таблице 1 приведены данные по розничному товарообороту Республики Беларусь за 2013-2019 годы, из которых следует, что товарооборот растет примерно на $10 \%$ ежегодно.

На рисунке 2 представлена гистограмма процентного соотношения ритейлеров в товарообороте в зависимости от их величины. Наблюдается динамика масштабизации, укрупнения розничной торговли в РБ, впрочем, следует отметить, что это общемировой тренд.

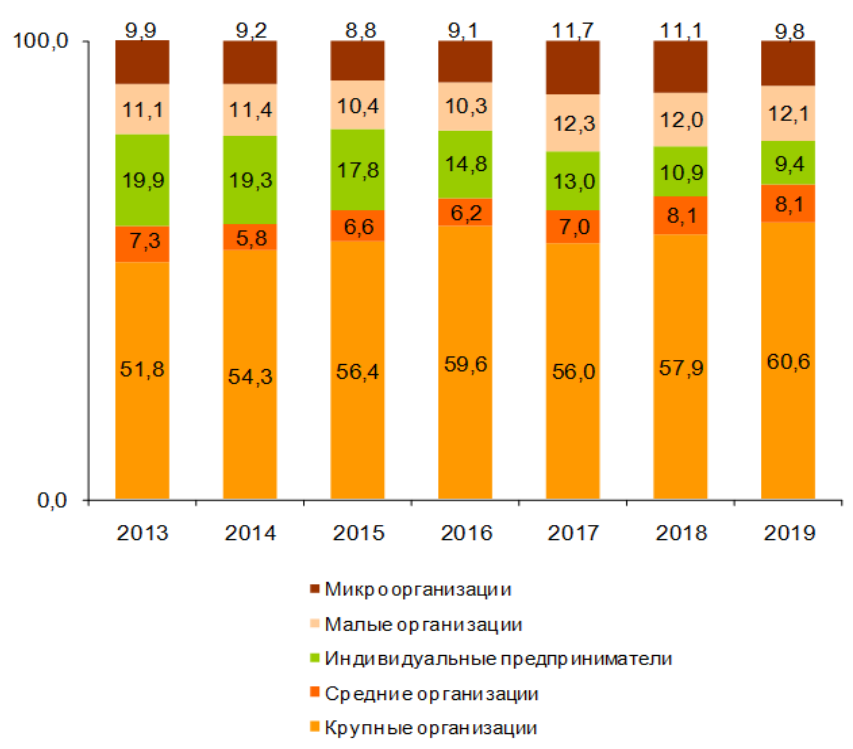

Рисунок 2 - Структура розничного товарооборота по величине организации Источник: составлено на основе [3]

Из таблицы 2 видно, что в товарообороте снижается удельный вес товаров отечественного производства в целом, однако наметилась тенденция роста доли непродовольственных товаров в их составе, что сказывается на внутреннем потреблении населения страны [3].

На рисунке 3 представлено практически паритетное соотношение продовольственных и непродовольственных товаров в целом в товарообороте страны (отечественного производства и импорта). Последние 4 года наблюдается динамика увеличения доли непродовольственных товаров, что говорит об увеличении доходов населения.

Из таблицы 3 можно сделать вывод, что товарооборот в г. Минске и областях демонстрирует положительную динамику.

Таким образом, анализ розничного товарооборота позволяет сделать вывод, что продажи в Республике Беларусь ежегодно растут примерно на $10 \%$, что свидетельствует о росте потребления населения. 
Вестник Брестского государственного технического университета. 2021 Таблица 1 - Розничный товарооборот по формам собственности (в фактически действовавших ценах)

\begin{tabular}{|c|c|c|c|c|c|c|c|}
\hline Товарооборот & 2013 & 2014 & 2015 & 2016 & 2017 & 2018 & 2019 \\
\hline \multicolumn{8}{|c|}{ млн руб., 2012-2015 гг. - млрд руб. } \\
\hline Розничный товарооборот & 268018,7 & 318100,0 & 347239,6 & 36923,4 & 40237,3 & 45165,2 & 49557,5 \\
\hline \multicolumn{8}{|l|}{$\begin{array}{l}\text { в том числе по формам } \\
\text { собственности: }\end{array}$} \\
\hline государственная & 24813 & 27263,0 & 28094,5 & 3086,1 & 3451,1 & 3954,3 & 4470,0 \\
\hline республиканская & 18983,9 & 21116,3 & 21997,7 & 2467,2 & 2815,8 & 3240,1 & 3722,5 \\
\hline коммунальная & 5829,6 & 6146,7 & 6096,8 & 618,9 & 635,3 & 714,2 & 747,5 \\
\hline частная & 210805,1 & 244095,8 & 259345,5 & 26687,3 & 28372,4 & 31212,6 & 29281,2 \\
\hline $\begin{array}{l}\text { из нее с долей } \\
\text { государственной } \\
\text { собственности }\end{array}$ & 24383,1 & 29415,9 & 29933,7 & 3136,2 & 3334,1 & 3468,7 & 3338,7 \\
\hline иностранная & 32400,1 & 46741,2 & 59799,6 & 7150,0 & 8413,8 & 9998,3 & 11138,5 \\
\hline \multicolumn{8}{|c|}{ в \% к итогу } \\
\hline Розничный товарооборот & 100 & 100 & 100 & 100 & 100 & 100 & 100 \\
\hline \multicolumn{8}{|l|}{$\begin{array}{l}\text { в том числе по формам } \\
\text { собственности: }\end{array}$} \\
\hline государственная & 9,2 & 8,6 & 8,1 & 8,3 & 8,6 & 8,8 & 10 \\
\hline республиканская & 7,1 & 6,7 & 6,3 & 6,6 & 7,0 & 7,2 & 8,3 \\
\hline коммунальная & 2,1 & 1,9 & 1,8 & 1,7 & 1,6 & 1,6 & 1,7 \\
\hline частная & 78,7 & 76,7 & 74,7 & 72,3 & 70,5 & 69,11 & 65,2 \\
\hline $\begin{array}{l}\text { из нее с долей } \\
\text { государственной } \\
\text { собственности }\end{array}$ & 9,1 & 9,2 & 8,6 & 8,5 & 8,3 & 7,7 & 7,4 \\
\hline иностранная & 12,1 & 14,7 & 17,2 & 19,4 & 20,9 & 22,1 & 24,8 \\
\hline
\end{tabular}

Источник: составлено на основе [3]

Таблица 2 - Удельный вес товаров отечественного производства в розничном товарообороте, в \%

\begin{tabular}{|c|c|c|c|}
\hline Годы & Всего & \multicolumn{2}{|c|}{ В том числе } \\
\hline & & Продовольственные товары & Непродовольственные товары \\
\hline 2017 & 58,4 & 69,0 & 31,0 \\
\hline 2018 & 57,2 & 64,4 & 35,6 \\
\hline 2019 & 56,4 & 62,8 & 37,2 \\
\hline
\end{tabular}

Источник: составлено на основе [3]

Таблица 3 - Розничный товарооборот по областям и г. Минск (в фактически действовавших ценах млн руб., 2012-2015 гг. - млрд руб.)

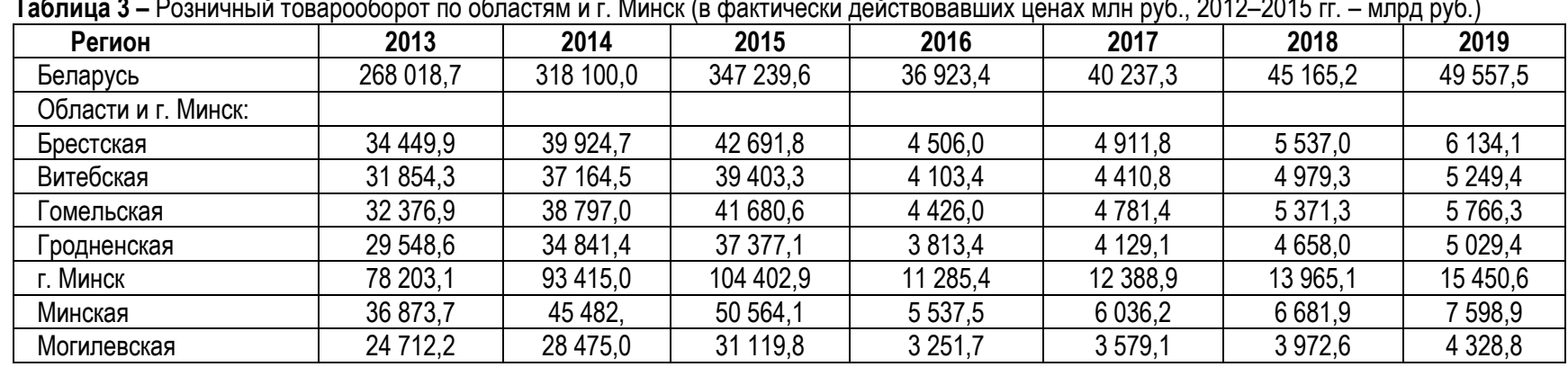

Источник: составлено на основе [3]

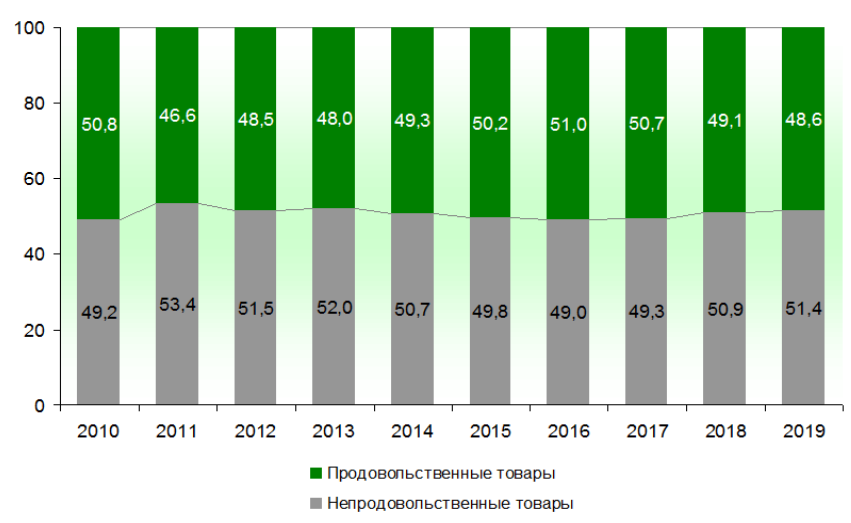

Рисунок 3 - Соотношение продовольственных и непродовольственных товаров в розничном товарообороте Источник: составлено на основе [3]
Методика формирования торговых розничных цепей и направления развития торговли

Практически до конца 20 столетия производители товаров широкого потребления имели большее влияние на рынок, чем торговля [4]. Сегодня же ситуация кардинально изменилась, и ритейлеры имеют определяющее влияние на рынок и на потребителя. Это связано со следующими процессами:

1. Глобализация торговли. Формирование торговых сетей (в Республике Беларусь - это «Евроопт», «Грошик» и т. д.).

2. Формирование сетевых торговых марок, которые успешно конкурируют с производственными марками.

3. Нехватка торговых площадей. Супермаркет предлагает 24 тыс. наименований товаров, а производители совокупно создают около 10 тыс. марок ежегодно.

4. Ритейлеры требуют все больше «бонусов» от производителей на продвижение товаров за свои услуги. В итоге у производителей остается меньше средств на рекламу.

5. Торговля аккумулирует собственные средства продвижения товаров (своя логистика, программное обеспечение, реклама и т. д.). 
6. Ритейлеры непосредственно влияют на потребителя, а в итоге и на поставщика. Занимают доминирующее положение в цепочках поставок.

Для дальнейшего повышения конкурентоспособности ритейлерам необходимо снижать затраты и увеличивать продажи. Минимизировать издержки возможно логистическим путем, формируя устойчивые, но гибкие цепи поставок. Наращение же продаж наиболее эффективно можно обеспечить ценовыми методами с использованием, в том числе, логистических инструментов «экономии», а также и неценовыми методами, что предполагает задействование методов и приемов современного маркетинга, а именно: оптимизации ассортиментной политики, совершенствования форм и методов продаж, мерчендайзинга, высокого уровня сервиса, рекламы.

Методику построения «эфффективного ритейла» можно описать следующими последовательными этапами:

Этап 1. Информационный этап. Собирается и анализируется информация о товарах, поставщиках, производителях, рынках, потребителях. Формируются требования к товарам и поставщикам.

Этап 2. Определяется товарооборот и требования к пропускной способности каналов на входе и выходе торговой логистической системы. Сколько товаров необходимо закупить и сколько планируется продать? Формируется ассортимент.

Этап 3. Определяется количество каналов сбыта. Планируются объемы оптовых продаж, розничных стационарных продаж, складских и транзитных, развозных, электронных продаж.

Этап 4. Определяется типы и виды торговых объектов. Рассчитывается торгово-технологическая площадь торговых объектов.

Этап 5. Выбираются оптимальные торгово-технологические процессы.

Этап 6. Распределяется товарная и технологическая площадь на торговых объектах.

Этап 7. Формируется система интенсификации продаж. Оптимизируется ассортимент.

Этап 8. Распределяются ресурсы: основные и оборотные средства, трудовые, энергетические и т. д.

Этап 9. Формируется система работы с поставщиками. Определяются требования к поставщику и формируются эффективные хозяйственные связи.

Этап 10. Определяются прямые цепи поставок. Именно прямые связи являются наиболее эффрективными. В тех ситуациях, где необходимые сроки и объемы поставок совпадают с возможными, заключаются соответствующие прямые договоры.

Этап 11. Определяются складские цепи поставок. Товар поступает на склад, а затем в торговый объект. Менее эффективная фрорма, но в конкретных условиях применима. Например розничная торговля с ограниченной торговой площадью, мелкооптовая или электронная торговля.

Этап 12. Определяются комбинированные цепи поставок. Склад с торговых объектов переносится на логистический центр, который распределяет товарные ресурсы между торговыми объектами, между поставщиками и торговыми объектами.

Этап 13. Формирование интегрированных цепей поставок. Создается логистический центр конкретного крупного сетевого ритейлера (например ЛЦ ООО «Санта-Брэмор», ТЛЦ «Евроопт»). Для средних и мелких продавцов синдикативное объединение может формироваться на кластерной основе. Возможно, на договорной основе с существующим логистическим центром.

Этап 14. Формирование транзитных цепей продаж. Мелкооптовые развозные, почтовые, электронные продажи осуществляются со склада.

Этап 15. Предоставление допродажных, торговых, послепродажных, дополнительных услуг. Формирование благоприятной среды торговли, качественного сервиса.

Этап 16. Оптимизация транспортного обслуживания. Рационализация централизованных и децентрализованных перевозок.

Основными направлениями развития торговой системы являются:

- снижение торговых издержек на основе формирования цепей поставок (этапы 10-13);

- увеличение товарооборота за счет формирования цепей продаж (этапы 14, 15);

- увеличение товарооборота посредством перевода складской площади в торгово-технологическую (этап 4-7);

- увеличение товарооборота путем расширения ассортимента (этап 2).

\section{Заключение}

Анализ экономических макропоказателей за 2019 год показал, что объем ВВП в текущих ценах составил 134,7 млрд руб. или 101,2 \% к уровню 2018 года в сопоставимых ценах, при этом индекс-десрлятор ВВП за 2019 год по отношению к предыдущему году равнялся 106,5\%. Участие розничной торговли в формировании ВВП за 2019 год составило 49,5 млрд руб. или $37 \%$.

В 2020 году ВВП Беларуси составил 147,61 млрд руб., или около 60 млрд долларов США и 99,1 \% к предыдущему году в сопоставимых ценах. Основными фракторами снижения ВВП послужили политические события и пандемия, повлекшая за собой падение темпов мировой торговли в целом. Доля розничного товарооборота в ВВП страны в 2020 году сократилась до $35 \%$. Доля работающих в торговле в общем числе занятого населения в экономике составила $14,2 \%$.

Для более корректной и объективной оценки роли торговли необходимо учитывать только добавленную стоимость. Удельный вес добавленной стоимость торговли в 2019 году - 9 \% в ВВП. Опыт развитых стран говорит о том, что этот показатель должен быть не ниже $15 \%$, следовательно необходимо активизировать существующие резервы роста торговли.

В работе была предложена поэтапная методика формирования новой торговой сети, либо оптимизации существующего ритейла, а также возможные перспективные направления развития розничной торговли Республики Беларусь.

\section{Список цитированных источников}

1. О государственном регулировании торговли и общественного питания в Республике Беларусь [Электронный ресурс]: Закон Республики Беларусь от 8 января 2014 г. № 128-3. - Режим доступа: http://pravo.by/document??guid=3871\&p0=H11400128/. - Дата доступа: 16.01.2021.

2. Об утверждении Концепции развития логистической системы Республики Беларусь на период до 2030 года [Электронный ресурс]: Постановление Совета Министров Республики Беларусь от 28.12.2017 №1024. - Режим доступа: http://pravo.by/upload/ docs/op/C21701024_1515531600.pdf/. - Дата доступа: 07.01.2021.

3. Розничная и оптовая торговля, общественное питание: Статистический сборник Республики Беларусь. Минск: Национальный статистический комитет Республики Беларусь, 2019. - 221 с. [Электронный ресурс]. - Режим доступа: https://www.belstat.gov.by/upload/iblock/2f3/2f3dd5a15091a0a42dc820e56d862170.pdf. - Дата доступа: 17.01.2021.

4. Организация и технология торговли : учебник / С. Н. Виноградова, О. В. Пигунова, С. П. Гурская [и др.] ; под редакцией С. Н. Виноградовой. - Минск : Вышэйшая школа, 2009. - 464 с.

\section{References}

1. O gosudarstvennom regulirovanii torgovli i obshchestvennogo pitaniya v Respublike Belarus' [Elektronnyj resurs]: Zakon Respubliki Belarus' ot 8 yanvarya 2014 g. № 128-Z. - Rezhim dostupa: http://pravo.by/document?guid=3871\&p0=H11400128/. - Data dostupa: 16.01.2021.

2. Ob utverzhdenii Koncepcii razvitiya logisticheskoj sistemy Respubliki Belarus' na period do 2030 goda [Elektronnyj resurs]: Postanovlenie Soveta Ministrov Respubliki Belarus' ot 28.12.2017 №1024. Rezhim dostupa: http://pravo.by/upload/ docs/op/C21701024_1515531600.pdf/. - Data dostupa: 07.01.2021.

3. Roznichnaya i optovaya torgovlya, obshchestvennoe pitanie: Statisticheskij sbornik Respubliki Belarus'. Minsk: Nacional'nyj statisticheskij komitet Respubliki Belarus', 2019. - 221 s. [Elektronnyj resurs]. Rezhim dostupa: https://www.belstat.gov.by/upload/-iblock/2f3/2f3dd5a15091a0a42dc820e56d862170.pdf. - Data dostupa: 17.01.2021.

4. Organizaciya i tekhnologiya torgovli : uchebnik / S. N. Vinogradova, O. V. Pigunova, S. P. Gurskaya [i dr.] ; pod redakciej S. N. Vinogradovoj. - Minsk : Vyshejshaya shkola, 2009. - 464 c.

Материал поступил в редакцию 19.02.2021 